Article

\title{
Study on the Prediction Method of the Ultra-Low-Cycle Fatigue Damage of Steel
}

\author{
Qin Tian ${ }^{1,2}$, Yanhua Liao ${ }^{2}, \mathrm{Xu} \mathrm{Xie}^{2, *}$ and Hanqing Zhuge ${ }^{2}$ \\ 1 School of Civil Engineering and Architecture, Nanchang University, Nanchang 330031, China; \\ tianqin224@ncu.edu.cn \\ 2 College of Civil Engineering and Architecture, Zhejiang University, Hangzhou 310012, China; \\ liaoyanhua12@gmail.com (Y.L.); 11512058@zju.edu.cn (H.Z.) \\ * Correspondence: xiexu@zju.edu.cn; Tel.: +86-0571-882-08705
}

Received: 23 December 2019; Accepted: 15 January 2020; Published: 18 January 2020

check for updates

\begin{abstract}
Cyclic void growth model (CVGM) and continuum damage mechanics (CDM) model are suitable for predicting the damage of ultra-low-cycle fatigue (ULCF) theoretically. However, studies on the prediction of ultra-low-cycle fatigue (ULCF) damage is lacking. To determine which method is better, we used the two methods to predict the damage of ULCF. Firstly, uniaxial tensile and large strain cycle tests were performed on the base metal, weld metal and heat-affected zone and the material parameters were calibrated respectively. The uniaxial plastic strain threshold and toughness parameter of weld metal were minimum, and the dispersion was maximum. The finite element models of the base metal and weld specimens were established based on the calibrated parameters, and the ULCF damage was predicted. Compared with the CVGM model, the CDM model can predict the fatigue life and the relationships among the fatigue and fracture lives, the post-fracture path and the number of cycles to initial damage. The parameter calibration is simple. CDM is superior to CVGM in predicting the ULCF damage of steel and its weld joints.
\end{abstract}

Keywords: steel; ultra-low cycle fatigue; prediction method; continuum damage mechanics; cyclic void growth model

\section{Introduction}

In the past earthquakes, the seismic damage of steel piers has led to ultra-low cycle fatigue (ULCF) damage at the weld joints in addition to the residual displacement caused by excessive plastic deformation and local buckling of steel piers [1]. For example, during the Kobe earthquake in 1995, ULCF damage was observed at the joints of the steel structures [1,2]. Since then, domestic and foreign researchers have conducted numerous studies on the local buckling of steel plate and the ULCF damage at weld joints. Local buckling failure has been solved [3,4], but ULCF damage is still being explored. In recent years, researchers have made a series of studies on the mechanism of low cycle fatigue (LCF) and ULCF damages of steel [5,6]. The LCF life ranges from $10^{2}$ to $10^{4}$ cycles, and the fracture mechanism is brittle failure [7]. ULCF failure is caused by the ductile failure of steel under high strain cyclic load after a cyclic plastic deformation of less than 100 cycles, and the fracture mechanism is ductile failure [8-12]. The fracture mechanism of steel with ULCF is different from that of LCF $[13,14]$. Thus, the damage prediction method suitable for LCF cannot be directly applied to ULCF. Therefore, research on the prediction method of ULCF must be urgently conducted.

At present, several methods can be used to predict fatigue life, such as traditional fracture mechanics, Coffin-Manson formula, micromechanics model and continuum damage mechanics (CDM) model. Early researchers have mainly used fracture mechanics to study the fracture properties of steel and its weld joints. The traditional fracture mechanics method assumes that the crack already 
exists and a high strain constraint exists at the crack tip; this method is mainly suitable for the study of brittle or pseudo-brittle fracture [15]. However, the prediction method is unsuitable for the ductile fracture problem [16,17]. In 1954, Coffin [18] and Manson [19] proposed the Coffin-Manson formula for predicting the LCF life of materials on the basis of the relationship between fatigue life and plastic strain amplitude. The Coffin-Manson formula is the main method of predicting the LCF life of steel and its accuracy has been verified by many test results; however, its prediction of the ULCF life of steel is biased $[20,21]$. The above-mentioned descriptions indicate that the traditional fracture mechanics method and the Coffin-Manson formula are unsuitable for the damage prediction of ULCF.

Micromechanical models have been proposed in recent years to accurately predict the ULCF life [22]. These models mainly include the cyclic void growth model (CVGM) [23] and the degraded significant plastic strain (DSPS) model [24]. The two models attribute ductile cracking to the process of micro-hole nucleation, expansion and aggregation, which can reflect the triaxial stress state and plastic strain characteristics of the structure [25]. CVGM assumes that stress triaxiality is a variable during loading, whilst DSPS model assumes otherwise. The prediction results of CVGM are more accurate because CVGM can simultaneously consider the effects of stress triaxial and cumulative plastic strain on damage accumulation [26]. CDM model is another approach to predict the damage of ULCF method. By introducing appropriate damage variables, CDM model can directly describe the macroscopic mechanical behaviour and process of damage evolution of materials by considering the effect of damage on the material constitutions [27-29]. CDM model is applicable not only to brittle fracture but also to ductile fracture [30].

According to the abovementioned analysis, the cyclic void growth model (CVGM) and continuum damage mechanics (CDM) are both suitable for predicting the damage of ULCF theoretically. However, the study on the prediction of ULCF damage is actually lacking. The comparison of the two methods in terms of the prediction accuracy of fatigue life, the complexity of parameter calibration and the relationship between fatigue and fracture lives is unclear. To determine the better method, we used the two methods to predict the damage of ULCF. Firstly, the material parameters of CDM and CVGM were calibrated on the basis of uniaxial tensile and strain cyclic loading tests. The finite element models suitable for CDM and CVGM were established on the basis of the calibration parameters. ULCF damage was predicted for the base metal and weld specimens. Compared with the CVGM model, the CDM model can predict the fatigue life and the relationships among fatigue and fracture lives, the post-fracture path and the number of cycles to initial damage. In addition, the parameter calibration is simple. CDM is superior to CVGM in predicting the ULCF damage of steel and its weld joints.

\section{Theoretical Model for ULCF of Structural Steel}

\subsection{CDM Model for ULCF}

The CDM model for ULCF in this study is shown as the following Equations (1-3) [29].

$$
\begin{gathered}
d D=\alpha \frac{\left(D_{c r}-D_{0}\right)^{1 / \alpha}}{\ln \left(\varepsilon_{f} / \varepsilon_{t h}\right)} f(T)\left(D_{c r}-D\right)^{(\alpha-1) / \alpha} \frac{d \varepsilon^{p+}}{\varepsilon^{p}} \\
\left\{\begin{array}{l}
d \varepsilon^{p+}=d \varepsilon^{p} \cdot H(T) \\
H(T)= \begin{cases}0 & T<0 \\
1 & T \geq 0\end{cases} \\
\varepsilon_{f}^{p}=\varepsilon_{t h}\left(\frac{\varepsilon_{f}}{\varepsilon_{t h}}\right)^{1 / f(T)}
\end{array}\right.
\end{gathered}
$$

where $D, D_{0}$ and $D_{c r}$ are the damage, initial damage and critical damage variables, respectively. $\alpha$ is the damage exponent characteristic of the material. $\varepsilon_{t h}$ represents the plastic strain threshold. $\varepsilon_{f}$ and $\varepsilon_{f}^{p}$ represent the fracture-accumulated plastic strain under uniaxial stress and the fracture-accumulated plastic strain under multiaxial stress, respectively. $T$ and $f(T)$ represent the stress triaxiality and stress 
triaxial function, respectively. $H(T)$ signifies the damage state. $\varepsilon^{p+}$ and $\varepsilon^{p}$ are the accumulated plastic tensile strain and the accumulated plastic strain, respectively.

\subsection{CVGM for ULCF}

On the basis of the void growth model, Kanvinde et al. [31] proposed a CVGM for predicting the ductile cracking of ULCF. For cyclic strain loading, the sign of stress triaxiality $(T)$ changes, that is, it is positive under tension and negative under compression.

Therefore, the cavity volume growth rate under cyclic strain loading can be expressed as Equation (4).

$$
\begin{gathered}
\mathrm{d} r / r=\operatorname{sign}(T) C \exp (|1.5 T|) \mathrm{d} \varepsilon_{p} \\
\operatorname{sign}(T)= \begin{cases}0 & T<0 \\
1 & T \geq 0\end{cases}
\end{gathered}
$$

where $r$ is the instantaneous void radius, $C$ represents the material constant, $\operatorname{sign}(T)$ describes the sign of stress triaxiality shown as Equation (5). When $T$ is positive, tensile strain exists in the material. Otherwise, compressive strain exists in the material.

Void radius during cyclic strain loading can be obtained by integrating Equation (6).

$$
\ln \left(r / r_{0}\right)_{\text {cyclic }}=\sum_{\text {tensile }} C_{1} \int_{\varepsilon_{1}}^{\varepsilon_{2}} \exp (|1.5 T|) d \varepsilon_{p}-\sum_{\text {compressive }} C_{2} \int_{\varepsilon_{1}}^{\varepsilon_{2}} \exp (|1.5 T|) d \varepsilon_{p}
$$

where $\varepsilon_{1}$ and $\varepsilon_{2}$ are the equivalent plastic strains at the beginning and end of the tension or compression cycle, respectively. $C_{1}$ and $C_{2}$ represent the expansion and contraction rates of micropores, respectively.

Owing to the lack of sufficient experimental data, Kanvinde et al. [31] assumed that the expansion and contraction rates of micropores are the same, which are consistent with the expansion rates of micropores in the case of monotonic tension $\left(C_{1}=C_{2}=C\right)$. Equation (13) can be changed to Equations (7) and (8).

$$
\begin{aligned}
\ln \left(r / r_{0}\right)_{\text {cyclic }} & =C \cdot\left[\sum_{\text {tensile }} \int_{\varepsilon_{1}}^{\varepsilon_{2}} \exp (|1.5 T|) d \varepsilon_{p}-\sum_{\text {compressive }} \int_{\varepsilon_{1}}^{\varepsilon_{2}} \exp (|1.5 T|) d \varepsilon_{p}\right] \\
V G I_{\text {cyclic }} & =\sum_{\text {tensile }} \int_{\varepsilon_{1}}^{\varepsilon_{2}} \exp (|1.5 T|) d \varepsilon_{p}-\sum_{\text {compressive }} \int_{\varepsilon_{1}}^{\varepsilon_{2}} \exp (|1.5 T|) d \varepsilon_{p}
\end{aligned}
$$

where $V G I_{\text {cyclic }}$ is the hole expansion index [31].

Under cyclic loading, critical hole expansion index $V G_{\text {cyclic }}^{\text {critical }}$ is defined as follows [31]:

$$
V G I_{\text {cyclic }}^{\text {critical }}=\eta \exp \left(-\lambda_{C V G M} \varepsilon_{p}^{\text {accumulated }}\right)
$$

where $\lambda_{C V G M}$ is the damage degradation parameter of materials under cyclic loading, $\eta$ represents the monotonic void growth 'capacity', that is, toughness parameters, and $\varepsilon_{p}^{\text {accumulated }}$ is the equivalent plastic strain at the beginning of each tension cycle.

When hole expansion index $V G I_{\text {cyclic }}$ exceeds critical hole expansion index $V G I_{\text {cyclic }}^{\text {critical }}$, the ductile cracking of ULCF occurs.

$$
V G I_{\text {cyclic }} \geq V G I_{\text {cyclic }}^{\text {critical }}
$$

The fracture index $F I_{C V G M}$ of CVGM is defined as Equation (11).

$$
F I_{C V G M}=V G I_{\text {cyclic }} / V G I_{\text {cyclic }}^{\text {critical }}
$$

When fracture index $F I_{C V G M} \geq 1$, the material has ULCF ductile cracks. 


\subsection{Material Property}

The constitutive model of the base metal and weld specimens under cyclic loading is mixed hardening model [32]. The model includes two parts, namely, nonlinear equivalent hardening and kinematic hardening, as shown in Figure 1. The model can simulate the strength evolution of materials under cyclic loading. Chaboche mixed hardening model can reflect the strength evolution of materials under cyclic loading.

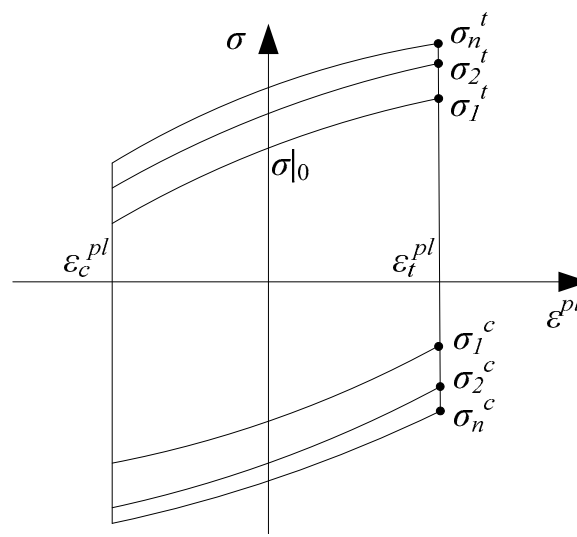

(a)

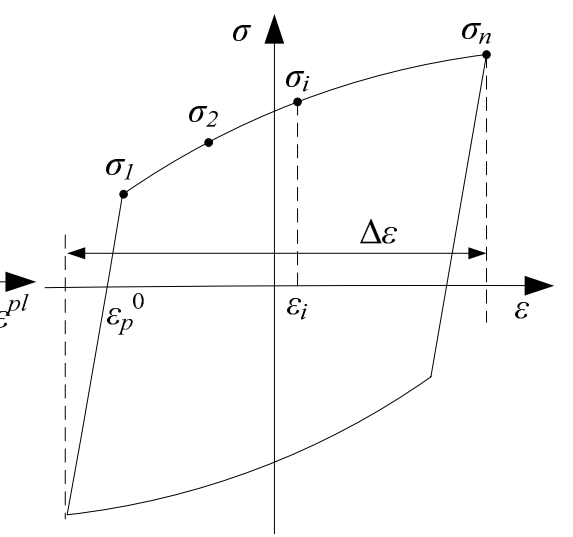

(b)

Figure 1. Chaboche mixed hardening model. (a) Nonlinear equivalent hardening. (b) Kinematic hardening.

The part of nonlinear equivalent hardening is represented by the change in yield surface. $\sigma^{0}$ is the nonlinear function of equivalent plastic strain $\varepsilon^{p}$.

$$
\sigma^{0}=\left.\sigma\right|_{0}+Q_{\infty}\left[1-\exp \left(-b \varepsilon^{p}\right)\right]
$$

where $\sigma^{0}$ represents the size of the initial yielding surface, $\left.\sigma\right|_{0}$ is the yield stress when the equivalent plastic strain is $0, Q_{\infty}$ is the maximum change value in yield surface and $b$ is the rate of change of the yield surface with the increase in equivalent plastic strain. The yield surface size $\sigma_{i}^{0}$ at circle $i(i=1,2,3, \ldots)$ is obtained by Equation (13).

$$
\sigma_{i}^{0}=\frac{\sigma_{i}^{t}-\sigma_{i}^{c}}{2}
$$

where $\sigma_{i}^{t}$ and $\sigma_{i}^{c}$ are the maximum tensile and compressive stresses at circle $i$, respectively.

$\varepsilon_{i}^{p}$ is the equivalent plastic strain corresponding to $\sigma_{i}^{0}$.

$$
\varepsilon_{i}^{p}=\frac{1}{2}(4 i-3) \Delta \varepsilon^{p}
$$

where $\Delta \varepsilon^{p}$ is the plastic strain range, which can be calculated by Equation (15).

$$
\Delta \varepsilon^{p} \approx \Delta \varepsilon-2 \sigma_{1}^{t} / E
$$

where $\Delta \varepsilon$ is the total strain.

The variation law of back stress $\alpha$ with equivalent plastic strain $\varepsilon^{p}$ is given in Equations (16) and (17).

$$
\begin{gathered}
\alpha_{k}=\frac{C_{k}}{\gamma_{k}}\left[1-\exp \left(-\gamma_{k} \varepsilon^{p}\right)\right]+\alpha_{k, 1} \exp \left(-\gamma_{k} \varepsilon^{p}\right) \\
\alpha=\sum_{k=1}^{N} \alpha_{k}
\end{gathered}
$$


where $\alpha_{k}$ is the ' $k$ 'th back stress, $\alpha_{k, 1}$ is the ' $k$ 'th back stress at the first data point and $C_{k} / \gamma_{k}$ is the maximum change value in the back stress. $\gamma_{k}$ determines the rate at which the back stress increases with the rise in plastic strain. Given that the shape of the curve varies greatly with different strain ranges, a more accurate curve can be obtained through multi-back stress superposition.

In data pairs $\left(\sigma_{i}, \varepsilon_{i}^{p}\right)$, back stress value $\alpha_{i}$ can be determined from Figure $1 \mathrm{~b}$.

$$
\alpha_{i}=\sigma_{i}-\sigma^{s}
$$

where $\sigma^{\mathcal{S}}$ is the average value of first data point $\sigma_{1}$ and last data point $\sigma_{n}$.

The equivalent plastic strain $\varepsilon_{i}^{p}$ is obtained by the following equation:

$$
\varepsilon_{i}^{p}=\varepsilon_{i}-\frac{\sigma_{i}}{E}-\varepsilon_{p}^{0}
$$

where $\varepsilon_{1}^{p}$ equals 0 , and $\varepsilon_{p}^{0}$ is the equivalent plastic strain value when the curve passes through the strain axis. Data pairs $\left(\alpha_{i}, \varepsilon_{1}^{p}\right)$ and $\left(\alpha_{1}, 0\right)$ should satisfy Equations (16) and (17). Material parameters $C_{k}$ and $\gamma_{k}$ can be obtained by fitting the test data.

According to the above-mentioned method, the Chaboche mixed hardening model parameters of Q345qC base metal, heat-affected zone (HAZ) and weld metal are calibrated, and the calibration results are shown in Table 1.

Table 1. Material parameters of mixed hardening model.

\begin{tabular}{cccccccccc}
\hline Material & $\begin{array}{c}\sigma \mid \mathbf{0} / \\
\mathbf{M P a}\end{array}$ & $\begin{array}{c}Q \infty / \\
\mathbf{M P a}\end{array}$ & $\boldsymbol{b}$ & $\begin{array}{c}C_{1} / \\
\mathbf{M P a}\end{array}$ & $\gamma_{1}$ & $\begin{array}{c}C_{2} / \\
\mathbf{M P a}\end{array}$ & $\gamma_{2}$ & $\begin{array}{c}C_{3} / \\
\mathbf{M P a}\end{array}$ & $\gamma_{3}$ \\
\hline Base metal & 354.10 & 13.2 & 0.6 & 44373.7 & 523.8 & 9346.6 & 120.2 & 946.1 & 18.7 \\
$\begin{array}{c}\text { Heat-affected } \\
\text { zone (HAZ) }\end{array}$ & 312.57 & 9.8 & 0.7 & 32242.4 & 199.2 & 3858.5 & 43.1 & 329.2 & 0.3 \\
Weld Metal & 428.45 & 17.4 & 0.4 & 12752.3 & 160.0 & 1111.2 & 160.0 & 630.5 & 26.0 \\
\hline
\end{tabular}

\subsection{Calibration of Material Parameters for CDM}

The uniaxial plastic strain threshold $\varepsilon_{t h}$ of the Q345qC base metal, HAZ and weld metal was calibrated by the uniaxial tensile tests [29]. The values of $\varepsilon_{t h}$ for the base metal, HAZ and weld metal are $0.4455,0.4357$ and 0.3673 . The value of $\varepsilon_{\text {th }}$ for the weld metal is the lowest, which is $17.56 \%$ and $15.70 \%$ less than those of the base metal and HAZ, respectively. The dispersion coefficient of weld metal is $34.84 \%$, thereby indicating that the weld metal has the largest material uniformity [29].

In addition, the distribution of equivalent plastic strain $\varepsilon^{p}$ and stress triaxiality $T$ at the root of the notch section is shown in Figure 2. Equivalent plastic strain $\varepsilon^{p}$ is nearly the same across the notch section in the case of notch radius $R=4.25 \mathrm{~mm}$ in Figure 2a. In the case of notch radii $R=3.0 \mathrm{~mm}$ and $R=1.5 \mathrm{~mm}$, the maximum equivalent plastic strain appears on the notch surface. Figure $2 \mathrm{~b}$ shows that the maximum stress triaxiality appears at the centre of the notch section and decreases to the notch surface. In the test, ductile initiation occurs at the centre of the notch section of all the notched specimens, and the equivalent plastic strain is the largest on the notched surface. Therefore, under the state of stress triaxiality, the equivalent plastic strain alone cannot be used for fracture prediction. 


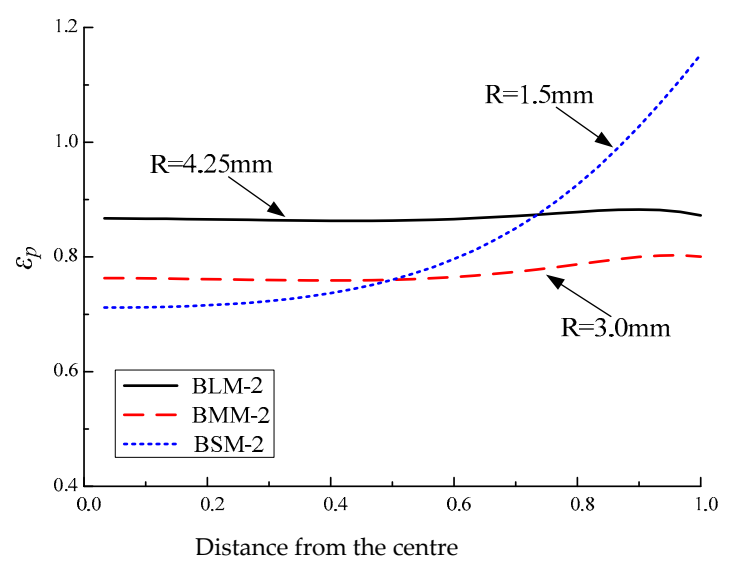

(a)

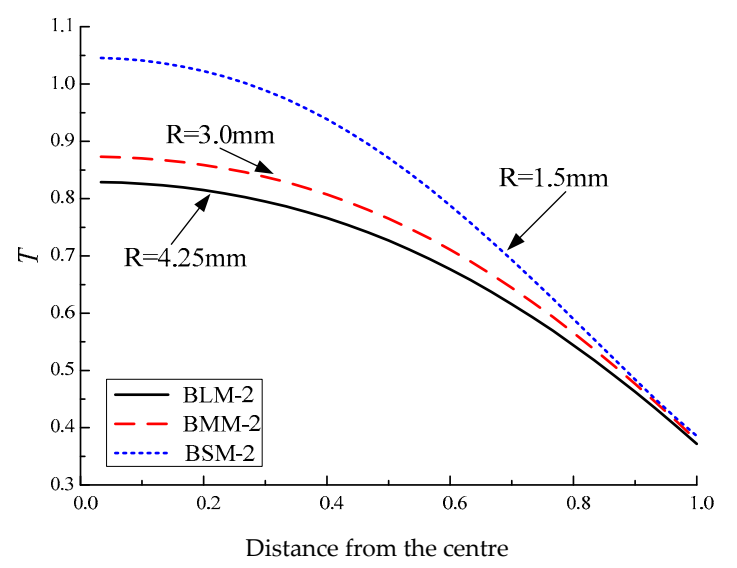

(b)

Figure 2. Distribution of equivalent plastic strain and stress triaxiality at the root of the notch section.

(a) Distribution of equivalent plastic strain. (b) Distribution of stress triaxiality.

\subsection{Calibration of Material Parameters for CVGM}

\subsubsection{Cycle Loading Test for Notched Round Bar Specimen}

Cyclic loading tests of the notched round bar specimens are required to calibrate damage degradation parameter $\lambda_{C V G M}$. The loading form is constant amplitude strain loading, and the strain ratio equals -1 . The loading form and fatigue life $N_{f}$ are recorded in the test [33].

\subsubsection{Calibration of Material Parameters for CVGM by Finite Element Analysis}

The two-dimensional axisymmetric finite element models of a notched round bar specimen for base metal, HAZ and weld metal are established, as shown in Figure 3, to calibrate toughness parameter $\eta$. The control deformation in the monotonic loading test is applied to the finite element analysis. Toughness parameter $\eta$ can be calibrated by Equation (20).

$$
\eta=\int_{0}^{\varepsilon_{p}^{\text {critical }}} \exp (1.5 T) \cdot d \varepsilon_{p}
$$

where $\varepsilon_{p}^{\text {critical }}$ is the critical equivalent plastic strain.

Calibration results of the material parameters for $\eta$ are shown in Table 2. The $\eta$ value of the base metal is slightly larger than that of HAZ and significantly larger than that of weld metal. This finding indicates that the fracture toughness of the base metal is the strongest, followed by that of HAZ and the weld metal is the weakest. The large dispersion coefficient of weld metal indicates that the welding quality is unstable.

In addition, the damage degradation parameter $\lambda_{C V G M}$ can be calibrated by the cyclic loading test and finite element analysis. The loading form in the cyclic loading test is applied to the finite element model in the analysis, and hole expansion index $V G I_{c y c l i c}$ is recorded when the cyclic number reaches the fatigue life $N_{f}$ of test. Assuming that $V G I_{c y c l i c}$ equals critical hole expansion index $V G I_{c y c l i c}^{\text {critical }}, \lambda_{C V G M}$ can be calibrated by Equation (16). 


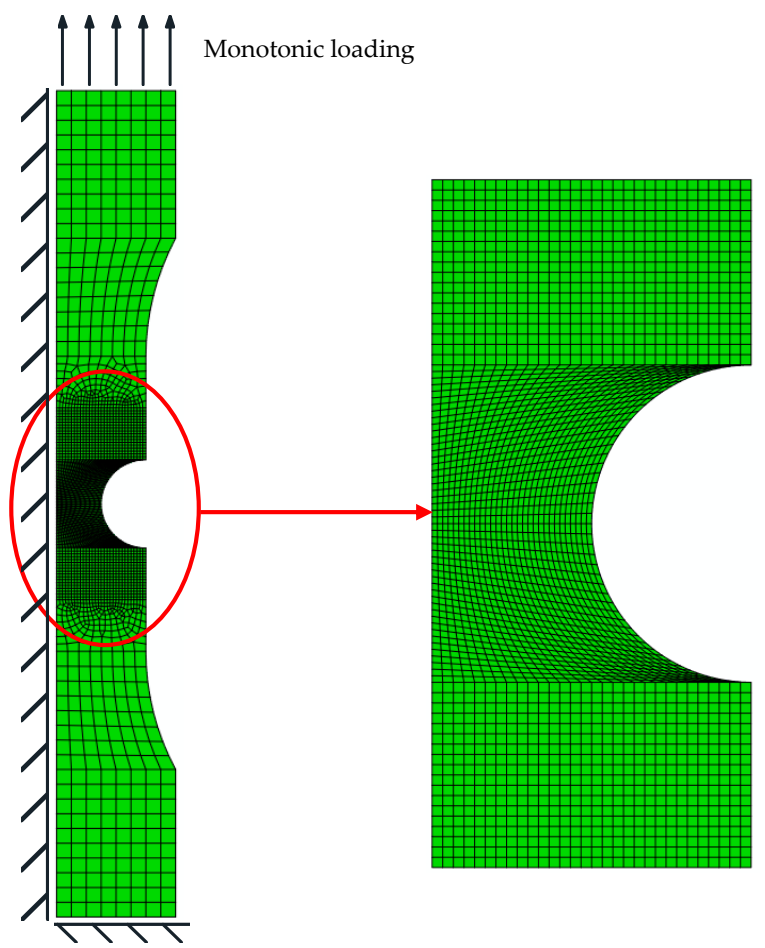

Figure 3. Two-dimensional axisymmetric finite element model of a notched round bar specimen.

Table 2. Calibration results of material parameters for $\eta$.

\begin{tabular}{|c|c|c|c|c|}
\hline Material & $R / \mathrm{mm}$ & Number & $\delta_{f} / \mathrm{mm}$ & $\eta$ \\
\hline \multirow{8}{*}{ Base metal } & \multirow{2}{*}{4.25} & BLM-1 & 2.240 & 2.981 \\
\hline & & BLM-2 & 2.262 & 3.000 \\
\hline & \multirow{2}{*}{3.0} & BMM-1 & 1.876 & 2.902 \\
\hline & & BMM-2 & 1.917 & 2.965 \\
\hline & \multirow{2}{*}{1.5} & BSM-1 & 3.543 & 3.280 \\
\hline & & BSM-2 & 3.477 & 3.163 \\
\hline & \multirow{2}{*}{\multicolumn{3}{|c|}{$\begin{array}{c}\text { Average } \\
\text { Dispersion coefficient }\end{array}$}} & 3.048 \\
\hline & & & & $4.7 \%$ \\
\hline \multirow{8}{*}{ Heat-affected zone } & \multirow{2}{*}{4.25} & HLM-1 & 2.098 & 2.759 \\
\hline & & HLM-2 & 1.934 & 2.576 \\
\hline & \multirow{2}{*}{3.0} & HMM-1 & 1.895 & 2.795 \\
\hline & & HMM-2 & 1.922 & 2.947 \\
\hline & \multirow{2}{*}{1.5} & HSM-1 & 3.808 & 3.242 \\
\hline & & HSM-2 & 4.009 & 3.536 \\
\hline & \multirow{2}{*}{\multicolumn{3}{|c|}{$\begin{array}{c}\text { Average } \\
\text { Dispersion coefficient }\end{array}$}} & 2.976 \\
\hline & & & & $11.9 \%$ \\
\hline \multirow{8}{*}{ Weld metal } & \multirow{2}{*}{4.25} & WLM-1 & 1.821 & 2.711 \\
\hline & & WLM-2 & 1.672 & 2.521 \\
\hline & \multirow{2}{*}{3.0} & WMM-1 & 1.371 & 2.591 \\
\hline & & WMM-2 & 1.306 & 2.454 \\
\hline & \multirow{2}{*}{1.5} & WSM-1 & 2.593 & 1.508 \\
\hline & & WSM-2 & 2.264 & 1.103 \\
\hline & \multirow{2}{*}{\multicolumn{3}{|c|}{$\begin{array}{c}\text { Average } \\
\text { Dispersion coefficient }\end{array}$}} & 2.148 \\
\hline & & & & $31.2 \%$ \\
\hline
\end{tabular}




\section{ULCF Life Prediction for the Q345qC Base Material and Weld Joints}

\subsection{Strain Cyclic Loading Test for Base Material and Welded Joints}

\subsubsection{Material of Test Specimen and Loading System}

The base material used in the test is Q345qC, and the national standard of welding wire is ER50-6. Butt welding with a $\mathrm{CO}_{2}$ gas shield is used in this test. The welding residual stress is eliminated by the post weld heat treatment method [33]. Figure 4 shows the size of the base metal and weld specimens.
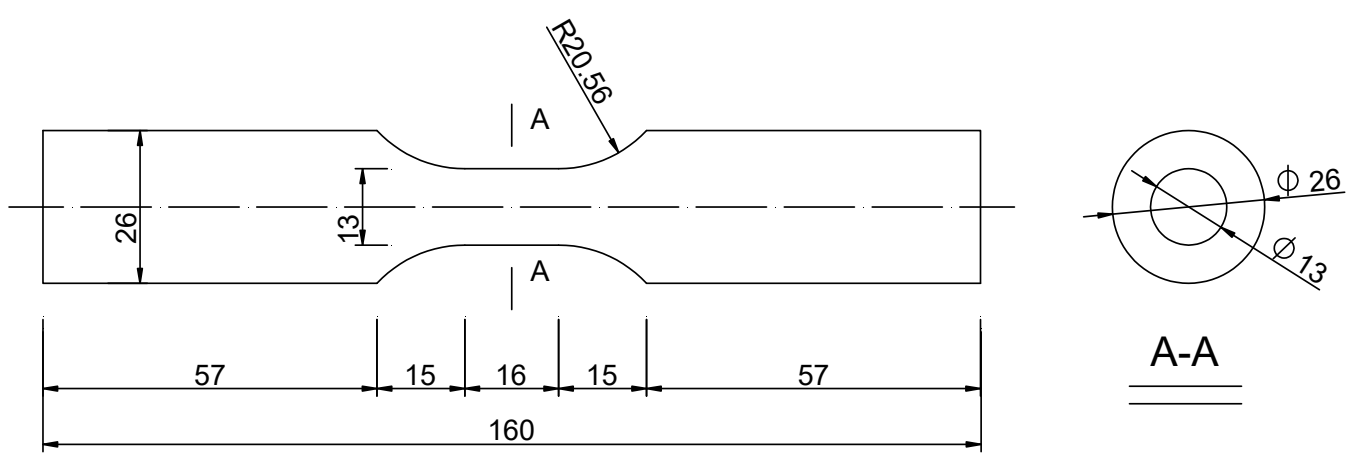

(a)
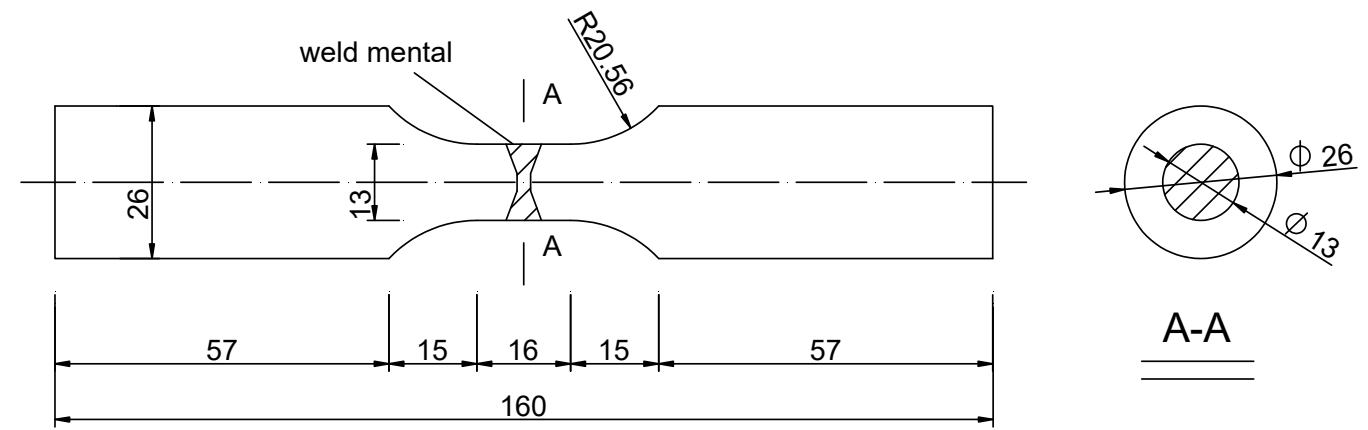

\section{A-A}

(b)

Figure 4. Size of specimens for ultra-low-cycle fatigue (ULCF) (unit: mm). (a) Base metal specimen and $(\mathbf{b})$ weld specimen.

The loading form is axial strain loading in which the strain ratio equals -1 . The strain loading rate is $0.5 \% / \mathrm{s}$. The strain amplitudes are $7 \%, 8 \%, 9 \%$ and $10 \%$ [33]. The numbers of BMC and WMC represent the base metal and weld specimens, respectively, as shown in Table 3.

\subsubsection{Test Results}

The crack initiation life $N_{f}$ and fracture life $N_{r}$ of the base metal and weld specimens and the ratio of $N_{f} / N_{r}$ are shown in Table 3. The average fatigue life $N_{f}^{\prime}$ decreases with the increase in strain range. The average fatigue life $N_{f}^{\prime}$ of the base metal specimen is greater than that of the weld specimen in the same strain range. In addition, the $N_{f} / N_{r}$ ratio is from $84.0 \%$ to $97.0 \%$, which indicates that the crack initiation stage occupies most of the cyclic loading stage. Fatigue cracking occurs at the edge of the cross section of the base metal specimen. The post-fracture path is perpendicular to the axis, as shown in Figure 5a. For the weld specimen, the fatigue crack originates in HAZ near the weld metal area. The post-fracture path shows that the cracks that originated at HAZ pass through the weld metal and extend to HAZ on the opposite side, and the cracks that formed on the weld specimen are diagonal, as shown in Figure 5b. 
Table 3. Test results for ULCF.

\begin{tabular}{|c|c|c|c|c|c|c|}
\hline$\Delta \varepsilon_{t} / \%$ & Number & $\begin{array}{l}\text { Crack Initial } \\
\text { Location }\end{array}$ & $\begin{array}{c}\text { Fatigue Life } \\
N_{f}\end{array}$ & $\begin{array}{l}\text { Fracture } \\
\text { Life } N_{r}\end{array}$ & $N_{f} / N_{r}$ & $\begin{array}{c}\text { Average } \\
\text { Fatigue Life } N_{f}^{\prime}\end{array}$ \\
\hline \multirow{6}{*}{7.0} & BMC01 & Section edge & 78 & 84 & $92.9 \%$ & \multirow{3}{*}{77} \\
\hline & ВMC03 & Section edge & 76 & 81 & $93.8 \%$ & \\
\hline & BMC21 & Section edge & 78 & 80 & $97.5 \%$ & \\
\hline & WMC04 & HAZ edge & 43 & 46 & $93.5 \%$ & \multirow{3}{*}{37} \\
\hline & WMC12 & HAZ edge & 40 & 42 & $95.2 \%$ & \\
\hline & WMC13 & HAZ edge & 29 & 34 & $85.3 \%$ & \\
\hline \multirow{6}{*}{8.0} & BMC05 & Section edge & 51 & 57 & $89.5 \%$ & \multirow{3}{*}{59} \\
\hline & BMC08 & Section edge & 55 & 57 & $96.5 \%$ & \\
\hline & BMC22 & Section edge & 72 & 75 & $96.0 \%$ & \\
\hline & WMC15 & HAZ edge & 32 & 35 & $91.4 \%$ & \multirow{3}{*}{32} \\
\hline & WMC18 & HAZ edge & 32 & 33 & $97.0 \%$ & \\
\hline & WMC21 & HAZ edge & 33 & 36 & $91.7 \%$ & \\
\hline \multirow{6}{*}{9.0} & BMC04 & Section edge & 47 & 51 & $92.2 \%$ & \multirow{3}{*}{44} \\
\hline & BMC17 & Section edge & 41 & 45 & $91.1 \%$ & \\
\hline & BMC18 & Section edge & 45 & 48 & $93.8 \%$ & \\
\hline & WMC03 & HAZ edge & 24 & 26 & $92.3 \%$ & \multirow{3}{*}{25} \\
\hline & WMC06 & HAZ edge & 29 & 31 & $93.5 \%$ & \\
\hline & WMC07 & HAZ edge & 24 & 25 & $96.0 \%$ & \\
\hline \multirow{6}{*}{10.0} & BMC15 & Section edge & 41 & 44 & $93.2 \%$ & \multirow{3}{*}{34} \\
\hline & BMC16 & Section edge & 30 & 31 & $96.8 \%$ & \\
\hline & BMC19 & Section edge & 33 & 35 & $94.3 \%$ & \\
\hline & WMC01 & Weld edge & 17 & 19 & $89.5 \%$ & \multirow{3}{*}{21} \\
\hline & WMC08 & Weld edge & 25 & 27 & $92.6 \%$ & \\
\hline & WMC20 & HAZ edge & 21 & 25 & $84.0 \%$ & \\
\hline
\end{tabular}

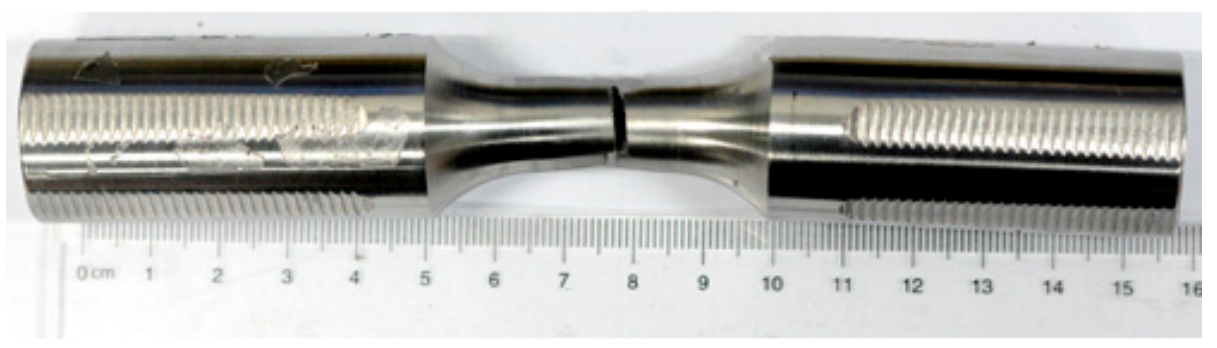

(a)

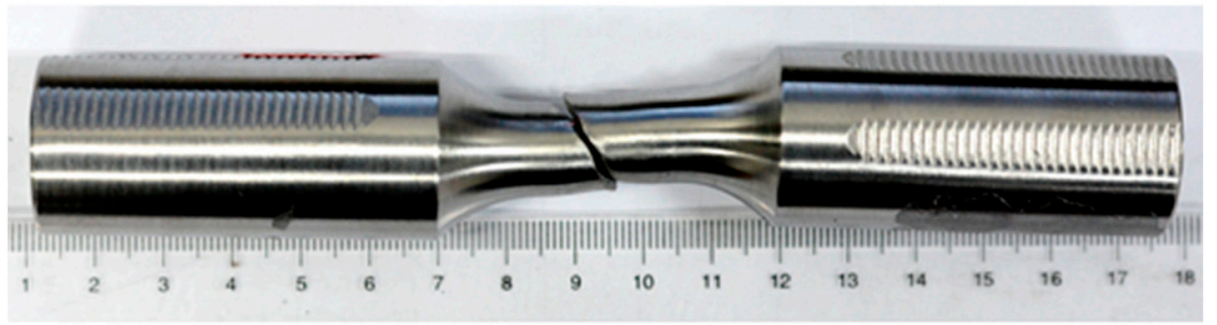

(b)

Figure 5. Post-fracture path of ULCF: (a) Base metal specimen and (b) weld specimen.

\subsection{ULCF Predictions for Base Material and Weld Joints}

\subsubsection{Establishment of a Finite Element Model}

Two-dimensional axisymmetric finite element model is modelled by ABAQUS, (Version 2016, Dassault Systèmes Simulia Corp., Johnston, RI, USA) as shown in Figure 3, to simulate the behaviour of 
the base metal specimen, and the monotonic loading is changed to cyclic loading. The weld specimen is modelled by a $3 \mathrm{D}$ finite element model, as shown in Figure 6 . The weld specimen includes weld metal, HAZ and base metal. Considering the calculation efficiency and accuracy, the weld specimen is modelled by a multi-scale model. The element size in the weld zone is small, and the element size far from the weld zone is large. The minimum element size is $0.2 \mathrm{~mm}$. Mixed hardening model is used to simulate the material constitutive model. Displacement loading mode is adopted in this analysis. The strain amplitudes are $7 \%, 8 \%, 9 \%$ and $10 \%$.

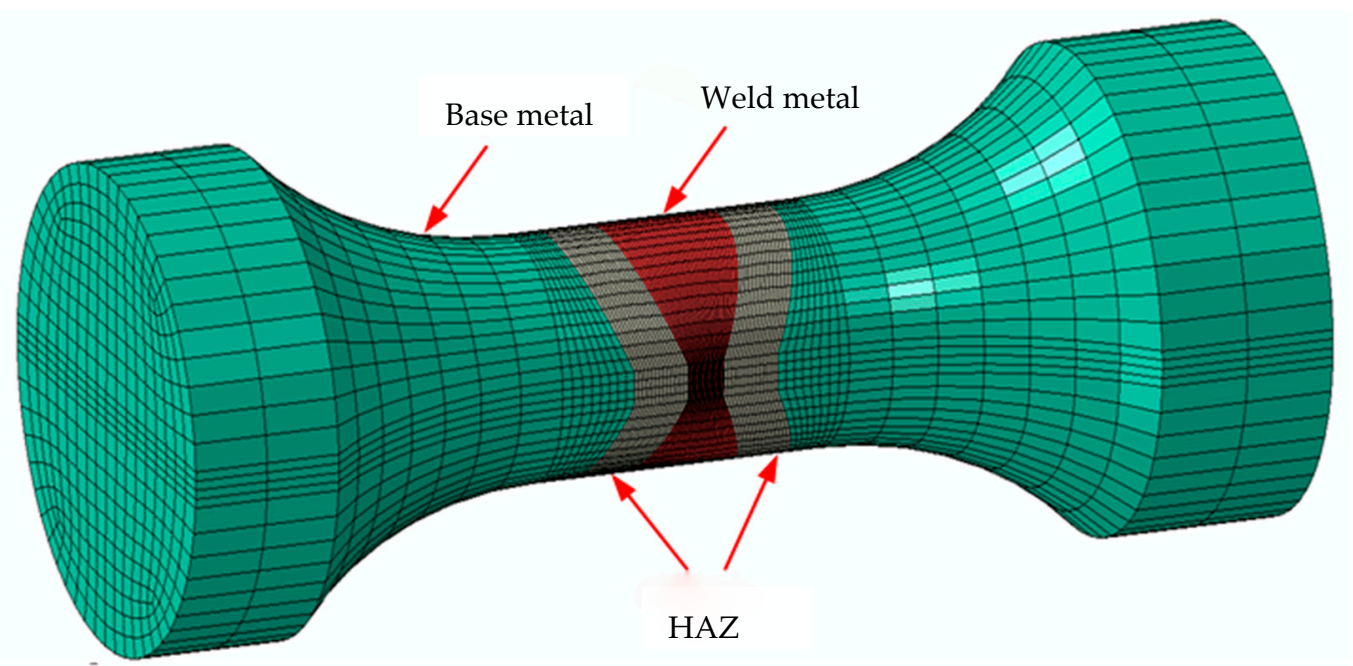

Figure 6. 3D finite element model of the weld specimen.

\subsubsection{Fatigue Life Prediction Based on the CDM Model}

The developments of the damage variable $D$ of the base metal and weld specimens at strain ranges of $7 \%, 8 \%, 9 \%$ and $10 \%$ are shown in Figures 7 and 8 , respectively. The base metal and weld specimens are not damaged when cumulative equivalent plastic strain $\varepsilon$ is less than uniaxial plastic strain threshold $\varepsilon_{t h}$. Therefore, damage variable $D$ equals 0 at the beginning of the cycle. The base metal and weld specimens exhibit damage when $\varepsilon$ is larger than $\varepsilon_{t h}$. According to Equation (8), only the damage caused by tensile strain is considered. Thus, $D$ exponentially increases with a stepped pattern. Under the same strain range, the $D$ value of the cross section centres of the base metal and weld specimens reach $D_{c r}$ earlier than that of the corresponding cross section edges. This result indicates that the predicted cracks originate from the cross section centre. CDM can predict not only the fatigue life $N_{f}$ but also the number of cycles to initial damage $N_{0}$. In addition, the $N_{f}$ and $N_{0}$ values of the base metal and weld specimens decrease gradually with the increase in total strain range. Given that $d D$ is proportional to $d \varepsilon^{p+}$, as shown in Equation (8), a large total strain range results in large $d D$ and $d \varepsilon^{p+}$, which leads to low $N_{0}$ and $N_{f}$. 


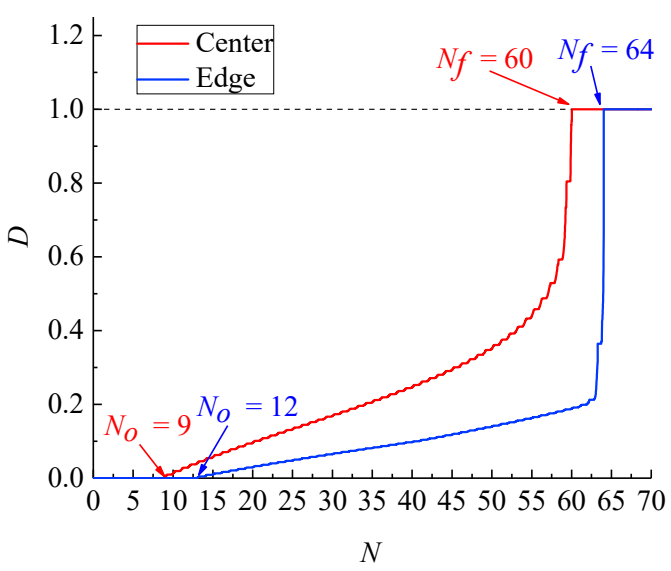

(a)

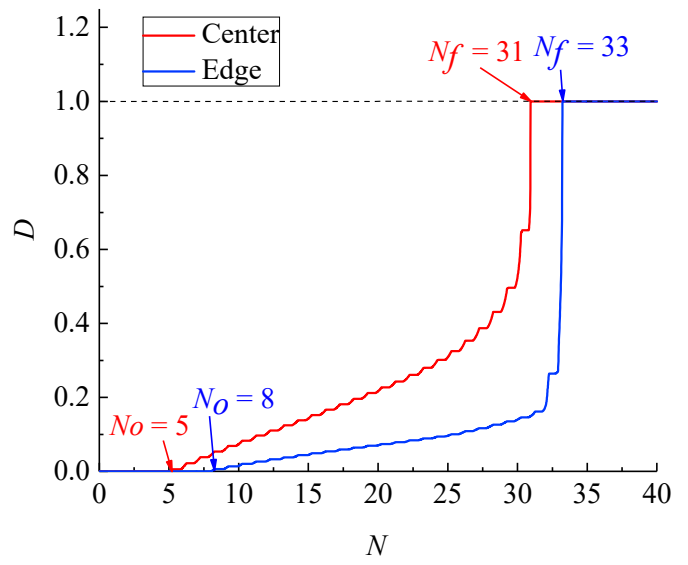

(b)

Figure 7. Development of the damage variable $D$ of the base metal specimen at strain ranges of (a) $7 \%$ and (b) $10 \%$.

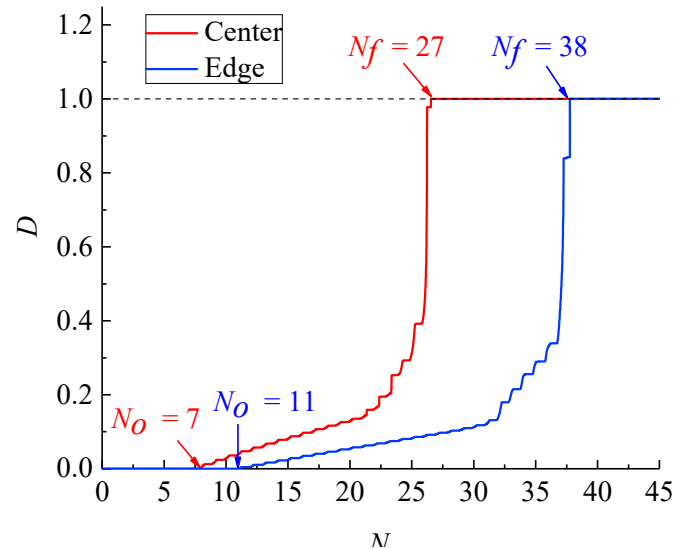

(a)

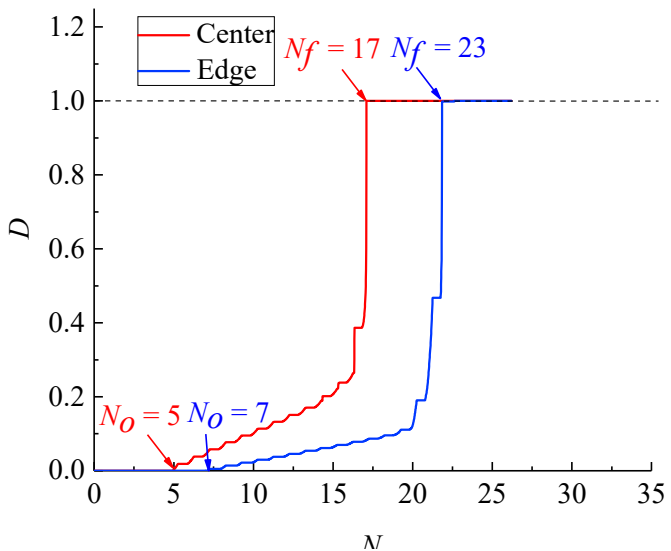

(b)

Figure 8. Development of the damage variable $D$ of the weld specimen at strain ranges of (a) $7 \%$ and (b) $10 \%$.

The comparisons of the predicted and test lives for the base metal and weld specimens are shown in Tables 4 and 5, respectively. $N_{f, C}^{P}$ and $N_{f, E}^{P}$ are the prediction fatigue lives at the cross section centre and edge, respectively. $N_{f}$ and $N_{r}$ are the test fatigue and fracture lives, respectively. Given that the value of $N_{f, C}^{P}$ is less than the value of $N_{f, E^{\prime}}^{P} N_{f, C}^{P}$ and $N_{f, E}^{P}$ can be considered the predicted fatigue and fracture lives, respectively. Similarly, $N_{f}^{p}$,WM is less than $N_{f,}^{p}$ HAZ. Thus, $N_{f, \text { WM }}^{p}$ and $N_{f,}^{p}$ HAZ can be considered the predicted fatigue and fracture lives, respectively. The error of the predicted and test fatigue lives decreases with the increase in strain. The proposed CDM is suitable for predicting the ductile fracture characteristics of materials, and a large strain range leads to highly ductile fracture characteristics of steel. Thus, the predicted fatigue and fracture lives are highly accurate in the case of large strain range. In the case of base metal and weld specimens, the predicted fatigue life is less than that in the test fatigue life. According to the comparisons in Tables 4 and 5, the predicted and test lives of the weld specimen are all less than those of the base metal specimen. 
Table 4. Comparison of predicted life with test life for base metal specimen in continuum damage mechanics (CDM).

\begin{tabular}{ccccccc}
\hline$\Delta \varepsilon t \%$ & $N_{f, C}^{P}($ Predicted) & $\begin{array}{c}N f \\
\text { (Test) }\end{array}$ & $\begin{array}{c}\text { Relative } \\
\text { Error (\%) }\end{array}$ & $N_{f, E}^{P}($ Predicted) & $\begin{array}{c}\boldsymbol{N r} \\
\text { (Test) }\end{array}$ & $\begin{array}{c}\text { Relative } \\
\text { Error (\%) }\end{array}$ \\
\hline 7.0 & 60 & 77 & -22.1 & 64 & 82 & -21.9 \\
8.0 & 47 & 59 & -20.3 & 50 & 63 & -20.6 \\
9.0 & 38 & 44 & -13.6 & 41 & 48 & -14.6 \\
10.0 & 31 & 35 & -11.4 & 33 & 37 & -10.8 \\
\hline
\end{tabular}

Table 5. Comparison of predicted life with test life for weld specimen in CDM.

\begin{tabular}{ccccccc}
\hline $\boldsymbol{\Delta} \boldsymbol{\varepsilon} \boldsymbol{t} \%$ & $\boldsymbol{N}_{\boldsymbol{f}, \mathbf{W M}}^{p}$ (Predicted) & $\begin{array}{c}\boldsymbol{N} f \\
\text { (Test) }\end{array}$ & $\begin{array}{c}\text { Relative } \\
\text { Error (\%) }\end{array}$ & $\boldsymbol{N}_{f, \text { HAZ }}^{p}$ (Predicted) & $\begin{array}{c}\boldsymbol{N} r \\
\text { (Test) }\end{array}$ & $\begin{array}{c}\text { Relative } \\
\text { Error (\%) }\end{array}$ \\
\hline 7.0 & 27 & 37 & -27.0 & 38 & 41 & -7.3 \\
8.0 & 26 & 32 & -18.8 & 33 & 35 & -5.7 \\
9.0 & 21 & 26 & -19.2 & 26 & 27 & -3.7 \\
10.0 & 17 & 21 & -19.0 & 23 & 24 & -4.2 \\
\hline
\end{tabular}

The relationships between the fatigue and fracture lives of the base metal and weld specimens in the CDM model are shown in Tables 6 and 7. $N^{p} f N^{p}{ }_{r}$ is the ratio of predicted fatigue life to the predicted fracture life, whilst $N_{f} / N_{r}$ is the ratio of the test fatigue life to the test fracture life. For the base metal specimen, the value of $N_{f}^{p} / N^{p}{ }_{r}$ is very near the value of $N_{f} / N_{r}$, both of which are over $90 \%$. The fatigue life of the base metal specimen takes up most of the fracture life. When crack initiates, the crack will expand rapidly and fracture after several cycles. For the weld specimen, the value of $N_{f} f_{f} N_{r}$ is between $71.0 \%$ and $78.8 \%$, whilst the test value is between $87.5 \%$ and $96.3 \%$. Therefore, the crack initiation life of the weld specimen still occupies most of the fracture life. Given the large dispersion of weld materials and the influence of the welding process, the error between the predicted and test values of the weld specimen is larger than that of the base metal specimen.

Table 6. Relationship between fatigue and fracture lives of the base metal specimen in the CDM model.

\begin{tabular}{ccccccc}
\hline \multirow{2}{*}{$\varepsilon_{t} / \%$} & \multicolumn{3}{c}{ Predicted } & \multicolumn{3}{c}{ Test } \\
\cline { 2 - 7 } & $\boldsymbol{N}_{\boldsymbol{f}}$ & $\boldsymbol{N}^{\boldsymbol{p}_{\boldsymbol{r}}}$ & $\boldsymbol{N}_{\boldsymbol{f}} / \boldsymbol{N}^{p_{r}}$ & $\boldsymbol{N}_{f}$ & $\boldsymbol{N}_{\boldsymbol{r}}$ & $\boldsymbol{N}_{f} / \boldsymbol{N}_{\boldsymbol{r}}$ \\
\hline 7.0 & 60 & 64 & $93.8 \%$ & 77 & 82 & $93.9 \%$ \\
8.0 & 47 & 50 & $94.0 \%$ & 59 & 63 & $93.7 \%$ \\
9.0 & 38 & 41 & $92.7 \%$ & 44 & 48 & $91.7 \%$ \\
10.0 & 31 & 33 & $93.9 \%$ & 35 & 37 & $94.6 \%$ \\
\hline
\end{tabular}

Table 7. Relationship between fatigue and fracture lives of the weld specimen in the CDM model.

\begin{tabular}{ccccccc}
\hline \multirow{2}{*}{$\Delta \varepsilon_{t} / \%$} & \multicolumn{3}{c}{ Predicted } & \multicolumn{3}{c}{ Test } \\
\cline { 2 - 7 } & $N^{p_{f}}$ & $N^{p_{r}}$ & $N^{p}{ }_{f} / N^{p_{r}}$ & $N_{f}$ & $N_{r}$ & $N_{f} / N_{r}$ \\
\hline 7.0 & 27 & 38 & $71.0 \%$ & 37 & 41 & $90.2 \%$ \\
8.0 & 26 & 33 & $78.8 \%$ & 32 & 35 & $91.4 \%$ \\
9.0 & 21 & 27 & $77.8 \%$ & 26 & 27 & $96.3 \%$ \\
10.0 & 17 & 23 & $73.9 \%$ & 21 & 24 & $87.5 \%$ \\
\hline
\end{tabular}

The post-fracture path is simulated, as shown in Figures 9 and 10, to analyse the fracture process of steel and its weld joint. For the base metal specimen, the difference between the number of cycles and fracture life is only 2-3 cycles when the crack width arrives at half of the base metal specimen width. This result indicates that the crack propagates rapidly. Cracks develop from the cross section centre to the edge, and their direction of development is perpendicular to the axis direction of the 
specimen. The predicted post-fracture path is consistent with the test results, as shown in Figure 5a. For the weld specimen, the crack initiates at the centre of the cross section. With the increase in cycle numbers, the fatigue crack develops from the centre of the cross section to the surface of the specimen, near the narrow weld metal zone. Then, the fatigue crack expands along the interface between the weld metal zone and HAZ. Lastly, an oblique crack is formed and thus leads to complete fracture. The test results in Figure 5b correctly demonstrate the post-fracture path of the weld specimens.

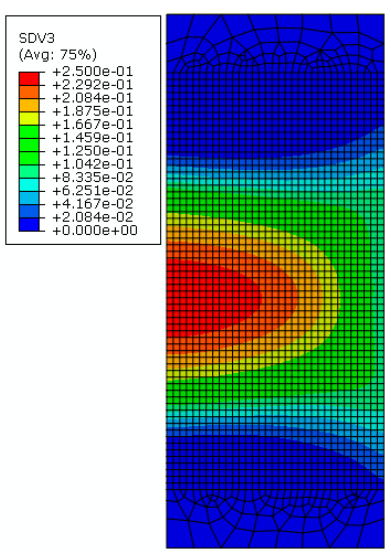

$N=26$

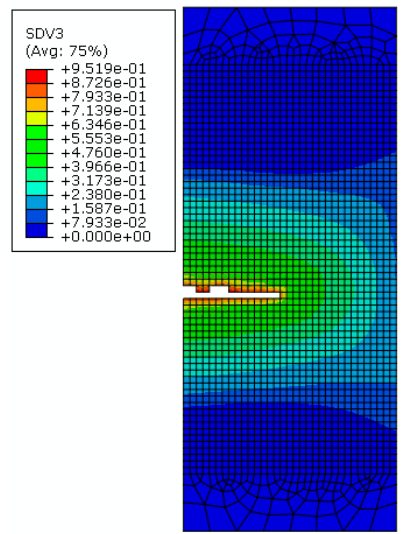

$N=39$

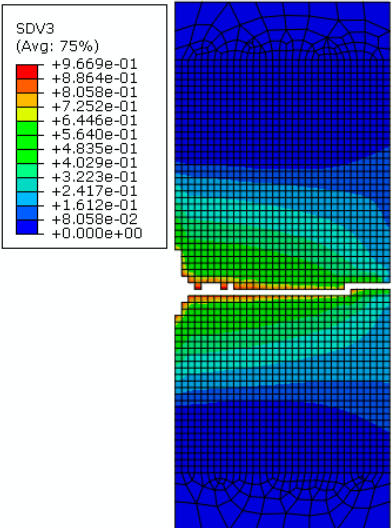

$N=41$

Figure 9. Development of cracks in the base metal specimen (strain range: $9 \%$ ).

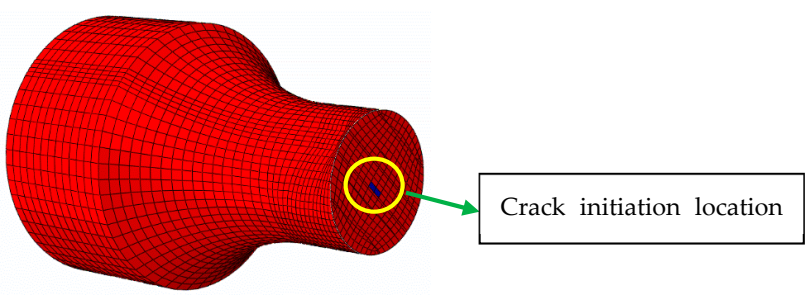

(a)

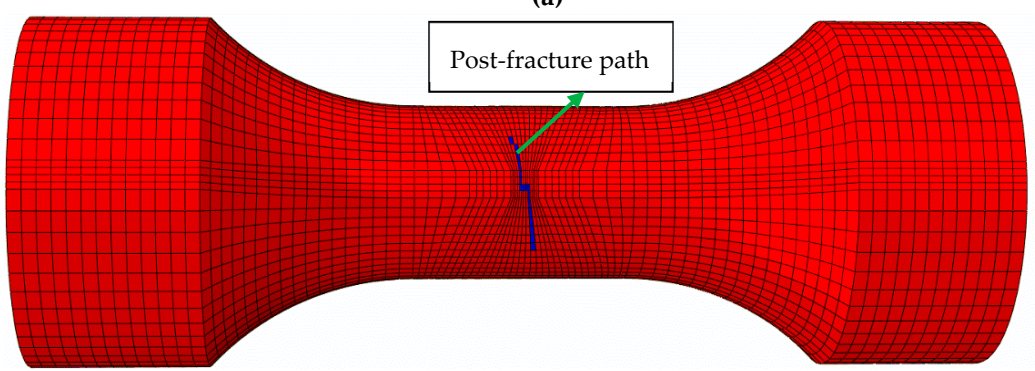

(b)

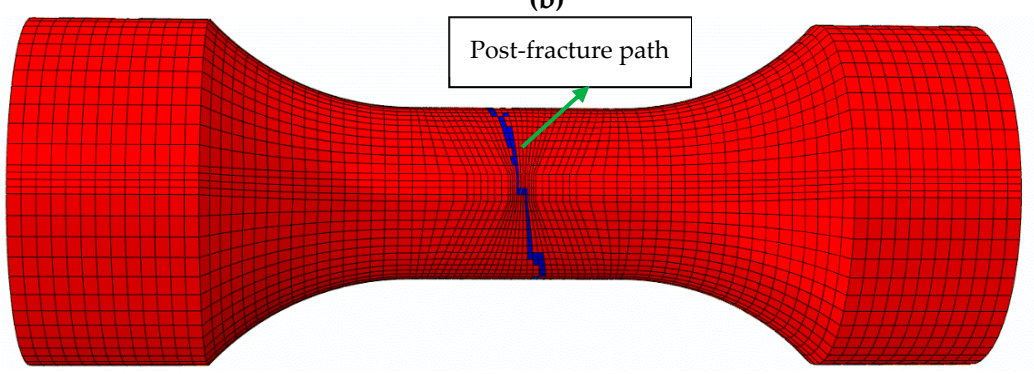

(c)

Figure 10. Development of cracks in the weld specimen (strain range, $7 \%$ ). (a) $N=27$, (b) $N=35$ and (c) $N=38$. 


\subsubsection{Fatigue Life Prediction Based on the CVGM}

The CVGM is used to predict the damage of ULCF for base metal and weld specimens under cyclic loads. On the basis of the calibrated parameters, such as toughness parameters $\eta$ and damage degradation parameter $\lambda_{C V G M}$, the finite element model is combined with CVGM. The finite element model is similar to CDM, as shown in Figures 3 and 6. The developments of the fracture index $F I_{C V G M}$ of CVGM for the base metal and weld specimens are shown in Figures 11 and 12. At the same strain level, the fracture index $F I_{C V G M}$ at the centre of the section grows faster than that at the edge. Thus, the cracks predicted by CVGM are generated at the centre of the section. At the same strain level, the damage index $F I_{C V G M}$ of the weld specimen increases the fastest in the weld metal zone, followed by that of HAZ and nearly no growth is observed in the base metal. Therefore, the predicted fatigue cracks start in the weld metal zone, whilst nearly all the fatigue cracks of the weld specimen start at the section edge of HAZ in the test. The above-mentioned analysis shows that the fatigue crack initiation point of the base metal and weld specimens predicted by CVGM is inconsistent with the test.

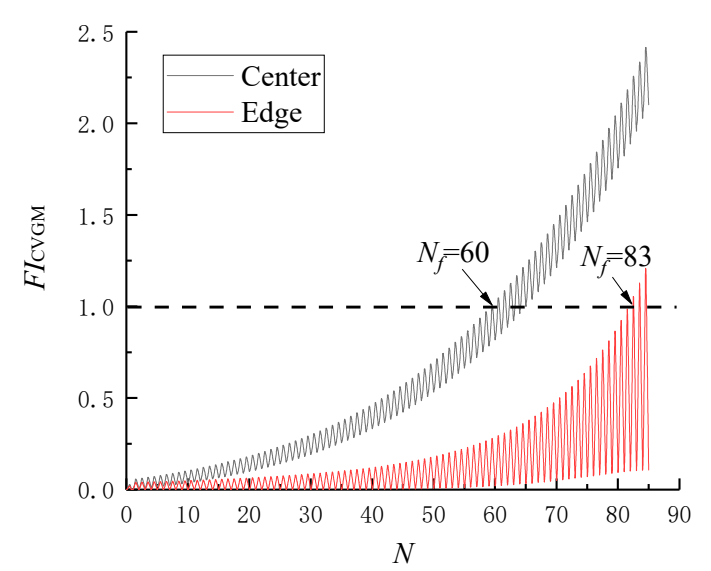

(a)

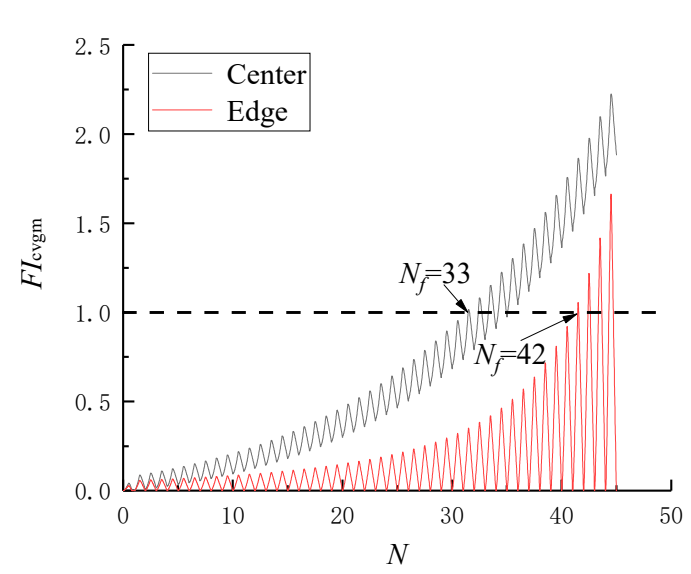

(b)

Figure 11. Development of the fracture index $F I_{C V G M}$ of base metal specimen. (a) $7 \%$ and (b) $10 \%$.

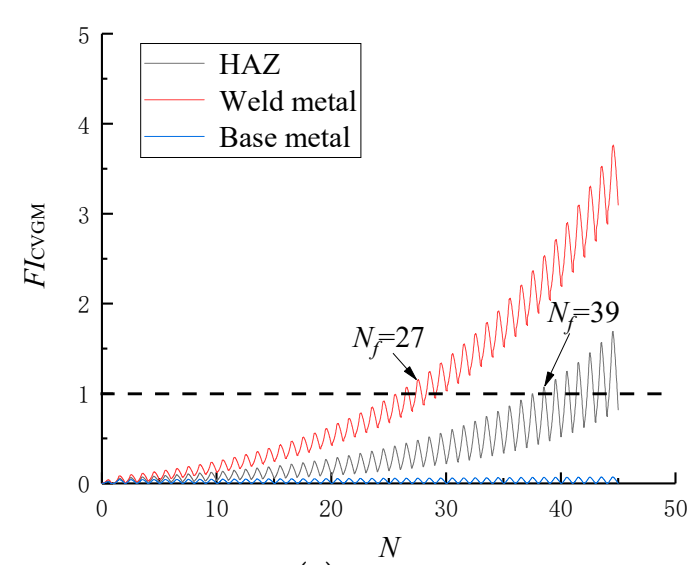

(a)

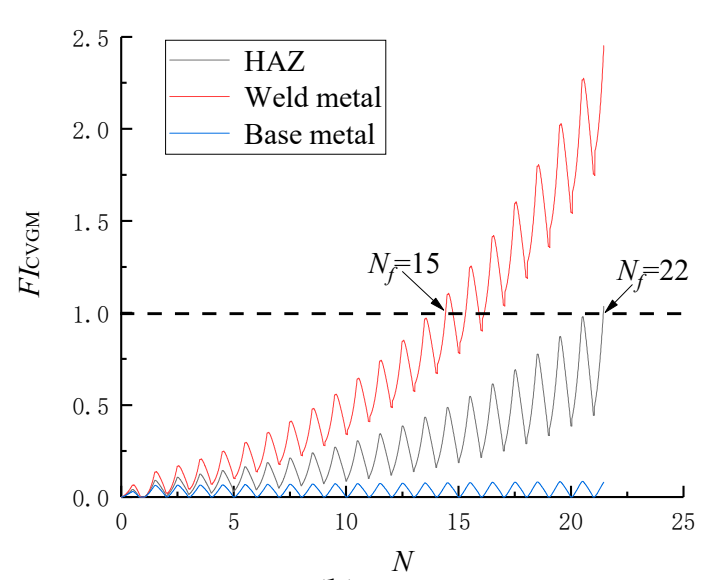

(b)

Figure 12. Development of the fracture index $F I_{C V G M}$ of weld specimen. (a) $7 \%$ and (b) $10 \%$.

The predicted life is compared with the test values, as shown in Tables 8 and 9, to further demonstrate the accuracy of CVGM in predicting the ULCF life. $N_{f, C}^{P}$ and $N_{f, E}^{P}$ are the prediction fatigue lives at the cross section centre and edge, respectively. $N_{f}$ and $N_{r}$ are the test fatigue and fracture lives, respectively. $N_{f}^{p}$ and $N_{r}{ }_{r}$ are the predicted fatigue and fracture lives, respectively. The predicted fatigue lives of weld metal $N_{f,}^{p}$ WM and HAZ $N_{f,}^{p}$ HAZ can be considered the predicted fatigue 
and fracture lives, respectively. For the base metal specimen in Table 8 , the predicted value of $N_{f, C}^{P}$ is less than the test fatigue life $N_{f}$ in all strain ranges. Moreover, the error of the predicted fatigue life to the test fatigue life decreases with the increase in the strain level. However, the predicted fracture life of the base metal specimen is greater than the test fatigue life, and the predicted results are relatively dangerous. For the weld specimen in Table 9, the predicted fatigue life $N_{f}^{p}$,WM is less than the test fatigue life $N_{f}$, and their relative error is greater than that of the base metal specimen. Predicted fracture life $N_{f}$ is opposite that of the base metal specimen and less than the test value.

Table 8. Comparison of predicted life with test life for base metal specimen in cyclic void growth model (CVGM).

\begin{tabular}{ccccccc}
\hline $\boldsymbol{\Delta} \boldsymbol{t} \boldsymbol{t} \%$ & $\boldsymbol{N}_{f, \boldsymbol{C}}^{\boldsymbol{P}}($ Predicted) & $\begin{array}{c}\boldsymbol{N} f \\
\text { (Test) }\end{array}$ & $\begin{array}{c}\text { Relative } \\
\text { Error (\%) }\end{array}$ & $\boldsymbol{N}_{f, \boldsymbol{E}}^{\boldsymbol{P}}($ Predicted) & $\begin{array}{c}\boldsymbol{N r} \\
\text { (Test) }\end{array}$ & $\begin{array}{c}\text { Relative } \\
\text { Error (\%) }\end{array}$ \\
\hline 7.0 & 60 & 77 & -22.1 & 83 & 82 & 1.2 \\
8.0 & 48 & 59 & -18.6 & 66 & 63 & 4.8 \\
9.0 & 40 & 44 & -9.1 & 56 & 48 & 16.7 \\
10.0 & 33 & 35 & -5.7 & 42 & 37 & 13.5 \\
\hline
\end{tabular}

Table 9. Comparison of predicted life with test life for weld metal specimen in CVGM.

\begin{tabular}{|c|c|c|c|c|c|c|}
\hline$\Delta \varepsilon t \%$ & $N_{f,}^{p}$ WM (Predicted) & $\begin{array}{c}N f \\
\text { (Test) }\end{array}$ & $\begin{array}{l}\text { Relative } \\
\text { Error }(\%)\end{array}$ & $N_{f, \text { HAZ }}^{p}$ (Predicted) & $\begin{array}{c}N r \\
\text { (Test) }\end{array}$ & $\begin{array}{l}\text { Relative } \\
\text { Error (\%) }\end{array}$ \\
\hline 7.0 & 27 & 37 & -27.0 & 39 & 41 & -4.9 \\
\hline 8.0 & 22 & 32 & -31.3 & 32 & 35 & -8.6 \\
\hline 9.0 & 17 & 26 & -34.6 & 27 & 27 & 0 \\
\hline 10.0 & 15 & 21 & -28.6 & 22 & 24 & -8.3 \\
\hline
\end{tabular}

Table 10 shows the comparison results between the value of $N^{p}{ }_{f} / N^{p}{ }_{r}$ calculated by CVGM and the test value of $N_{f} / N_{r}$. Table 10 indicates that the ratio of the predicted crack initiation life to the fracture life is $71.4 \%-78.6 \%$, which is less than the ratio of $91.7 \%-94.6 \%$ in the test, with a large difference. For the weld specimen, Table 11 shows that the CVGM-predicted value of $N^{p} / N^{p}{ }_{r}$ is $63.0 \%-69.2 \%$, which is less than the test ratio of $87.5 \%-96.3 \%$, and the error of both is more than that of the base metal specimen.

Table 10. Relationship between fatigue and fracture lives of base metal specimen in CVGM.

\begin{tabular}{ccccccc}
\hline \multirow{2}{*}{$\Delta \varepsilon_{t} / \%$} & \multicolumn{3}{c}{ Predicted } & \multicolumn{3}{c}{ Test } \\
\cline { 2 - 7 } & $N^{p_{f}}$ & $N^{p_{r}}$ & $N^{p_{f}} / N^{p_{r}}$ & $N_{f}$ & $N_{r}$ & $N_{f} / N_{r}$ \\
\hline 7.0 & 60 & 83 & $72.3 \%$ & 77 & 82 & $93.9 \%$ \\
8.0 & 48 & 66 & $72.7 \%$ & 59 & 63 & $93.7 \%$ \\
9.0 & 40 & 56 & $71.4 \%$ & 44 & 48 & $91.7 \%$ \\
10.0 & 33 & 42 & $78.6 \%$ & 35 & 37 & $94.6 \%$ \\
\hline
\end{tabular}

Table 11. Relationship between fatigue and fracture lives of weld metal specimen in CVGM.

\begin{tabular}{ccccccc}
\hline \multirow{2}{*}{$\Delta \varepsilon_{t} / \%$} & \multicolumn{3}{c}{ Predicted } & \multicolumn{3}{c}{ Test } \\
\cline { 2 - 7 } & $N^{p_{f}}$ & $N^{p_{r}}$ & $N^{p}{ }_{f} / N^{p_{r}}$ & $N_{f}$ & $N_{r}$ & $N_{f} / N_{r}$ \\
\hline 7.0 & 27 & 39 & $69.2 \%$ & 37 & 41 & $90.2 \%$ \\
8.0 & 22 & 32 & $68.8 \%$ & 32 & 35 & $91.4 \%$ \\
9.0 & 17 & 27 & $63.0 \%$ & 26 & 27 & $96.3 \%$ \\
10.0 & 15 & 22 & $68.2 \%$ & 21 & 24 & $87.5 \%$ \\
\hline
\end{tabular}

The above-mentioned analysis indicates CVGM can predict the fatigue life (with also the crack initiation life) and fracture life but cannot predict the relationship between fatigue and fracture lives, 
the number of cycles to initial damage and the post-fracture path. The error between the predicted and test values of the weld specimen is greater than that of the base metal specimen.

\subsubsection{Comparison of Two Fatigue Life Prediction Methods}

Figure 13 presents a comparison of the predicted lives of CDM and CVGM with the test life. For the base metal specimen in Figure 13a, (1) the predicted crack initiation lives from the two methods are less than the test values, and the predicted accuracy is relatively near. The error between the predicted crack initiation life and the test value decreases with the increase in the strain range. (2) In the case of fracture life, the predicted value of CDM model is less than the test value, and the predicted result is safe; the predicted value of CVGM is larger than the test value, and the predicted result is unsafe. With the increase in the total strain range, the error between the predicted fracture life of CDM model and the test value decreases, whilst the error between the predicted fracture life of CVGM and the test value increases. (3) In the case of the predicted ratio of crack initiation life to fracture life, the ratio in the test exceeds $90 \%$. The CDM model is more accurate in predicting the ratio than CVGM.

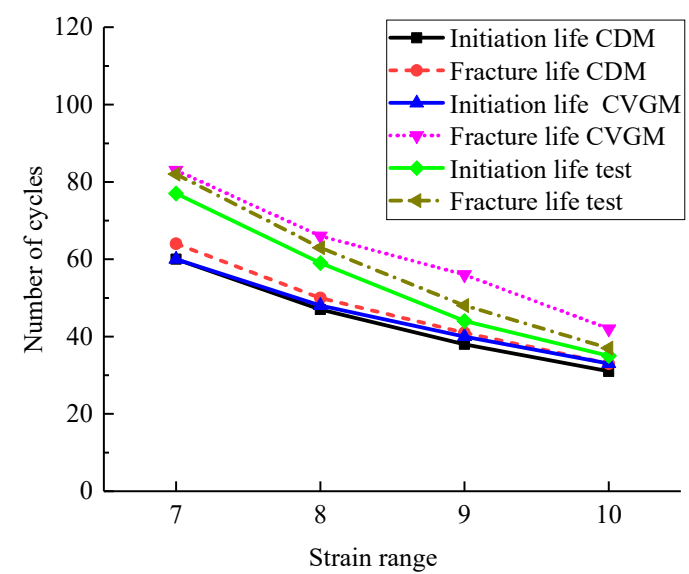

(a)

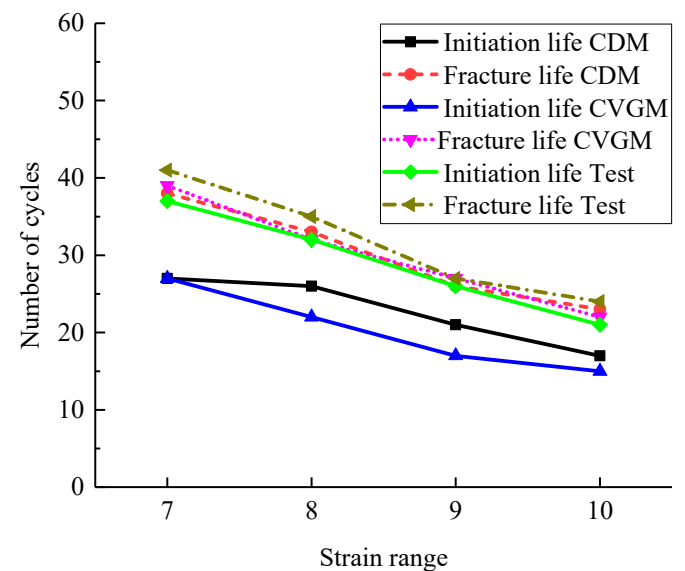

(b)

Figure 13. Comparison of predicted life of CDM and CVGM with test life. (a) Base metal specimen and (b) weld specimen.

For the weld specimen in Figure 13b, (1) the crack initiation life predicted by the CDM model is nearer the test value than that of CVGM, and the error between the crack initiation life predicted by the CDM and the test value decreases with the increase in the strain range. (2) In the case of predicting the fracture life of the weld specimen, the prediction results of the two methods are both less than the test values, and the error between the predicted fracture life by CDM and the test value is very small. (3) Similar to the base metal specimen, the ratio of crack initiation life to fracture life predicted by the CDM model is more accurate than that predicted by CVGM.

The CDM model can predict the number of cycles to initial damage of the base metal and weld specimens, whilst CVGM cannot. The prediction results by the CDM model are shown in Figure 14 . The number of cycles to initial damage of the cross-section centre of the base metal and weld specimens and the cross section edge of the base metal and weld specimens decrease with the increase in the strain range. The number of cycles to initial damage at the cross section centre of the base metal specimen is less than that at the cross section edge of the base metal specimen. Thus, the centre of the base metal specimen is the crack initiation point, and the edge of the base metal specimen is the crack fracture point. Similar to the base metal specimen, the number of cycles to initial damage at the centre of the weld specimen is less than that at the weld edge of the weld specimen. 


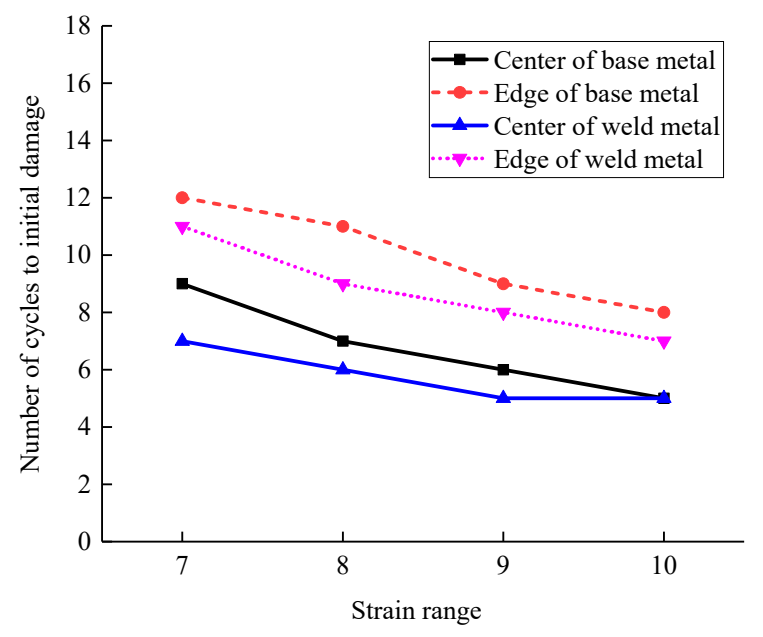

Figure 14. CDM model predicts the number of cycles to initial damage of base metal and weld specimens.

The prediction accuracy of fatigue life and the relationship between fatigue and fracture lives of the CDM model are better than those of CVGM. Given that the CDM must only perform the uniaxial monotonic tensile test of the notched round bar specimen and calibrate the plastic strain threshold under uniaxial stress $\varepsilon_{t h^{\prime}}$ the complexity of the parameter calibration process is simple. The finite element model is established, and the model can be used to predict the ULCF damage of the base metal and weld specimens. In addition, the CDM model can directly consider the influence of damage on the elastic modulus of materials and directly combine with the finite element software and is thus easy to apply in engineering. CVGM is a semi-empirical and -theoretical formula and requires many parameter calibration tests. Uniaxial monotonic tensile test and strain cyclic loading test must be performed to calibrate the damage degradation parameter and toughness parameter $\eta$. Compared with the CDM model, more parameters are calibrated, which leads to greater error. When establishing the finite element model, the characteristic length should be determined by combining with the scanning results of the electron microscope scanner on the base metal specimen and the fracture of the weld specimen. The finite element mesh is divided depending on the characteristic length in CVGM and is very small, and the calculation efficiency is low.

\section{Conclusions}

The finite element models of the base metal and weld specimens suitable for predicting ULCF were established on the basis of the calibrated parameters of CDM and CVGM. The predicted value of the damage under strain cyclic loading was compared with the test results to prove the effectiveness of the two prediction methods. The CDM model is better than CVGM in terms of predicting the damage of ULCF for steel and its joint. The specific research conclusions are as follows:

(1) Under stress triaxiality state, only the equivalent plastic strain cannot be used for fracture prediction. The crack initiation stage occupies most of the fracture life in the test.

(2) The value toughness parameter $\eta$ in CVGM for weld metal are the least one, and the dispersion coefficient of weld metal is the largest, thereby indicating that the weld metal can be easily damaged and has a large material uniformity.

(3) The location of cracks initiation predicted by the CDM model for the base metal and weld specimens is slightly different from the test results, but the predicted post-fracture path and fracture surface are consistent with the test results. The CDM model can also predict the relationship between the crack initiation and fracture lives.

(4) CVGM can predict the crack initiation and fracture lives well but cannot predict the relationship between the crack initiation and fracture lives and the post-fracture path. In addition, the location 
of the cracks initiation predicted by CVGM for the base metal and weld specimens is different from the test results.

(5) Compared with the CVGM model, the CDM model can predict the fatigue life and the relationship between fatigue and fracture lives, the post-fracture path and the number of cycles to initial damage. In addition, the parameter calibration is simple, and the prediction error is small. The finite element size is not limited by the characteristic length, and the calculation efficiency is high. $\mathrm{CDM}$ can directly consider the effect of damage on the elastic modulus of materials and can be combined easily with the finite element software for easy engineering application.

Author Contributions: Conceptualization, Q.T.; methodology, Q.T. and X.X.; software, Q.T. and Y.L.; validation, Y.L. and H.Z.; formal analysis, Q.T. and Y.L.; resources, X.X.; data curation, Q.T. and Y.L.; writing-original draft preparation, Q.T., Y.L. and X.X.; writing-review and editing, Q.T.; project administration, Q.T.; funding acquisition, Q.T. and X.X. All authors have read and agreed to the published version of the manuscript.

Funding: This research was funded by Natural Science Foundation of China, grant number 51878606; National Science Foundation for Young Scientists of Jiang Xi, grant number 20161BAB216113; Natural Science Foundation of Jiang Xi, grant number 20171BAB206050; and China Postdoctoral Science Foundation, grant number 2017 M611993.

Conflicts of Interest: The authors declare no conflict of interest.

\section{References}

1. Subcommittee on Investigation of Seismic Damage of Steel Structure. Investigation of causes of damage to steel structure on Hanshin-Awaji earthquake disaster. Proc. JSCE 2000, 64, 17-30.

2. Miller, D.K. Lessons learned from the Northridge earthquake. Eng. Struct. 1998, 20, 249-260. [CrossRef]

3. Goto, Y.; Ebisawa, T.; Lu, X.L. Local buckling restraining behavior of thin-walled circular CFT columns under seismic loads. J. Struct. Eng. 2014, 140,1-14. [CrossRef]

4. Usami, T.; Ge, H.B.; Saizuka, K. Behavior of partially concrete-filled steel bridge piers under cyclic and dynamic loading. J. Constr. Steel Res. 1997, 41, 121-136. [CrossRef]

5. Tong, L.; Huang, X.; Zhou, F.; Chen, Y. Experimental and numerical investigations on extremely-low-cycle fatigue fracture behavior of steel welded joints. J. Constr. Steel Res. 2016, 119, 98-112. [CrossRef]

6. Pereira, J.; De Jesus, A.M.; Fernandes, A. A new ultra-low cycle fatigue model applied to the X60 piping steel. Int. J. Fatigue 2016, 93, 201-213. [CrossRef]

7. Kuwamura, H.; Takagi, N. Similitude law of prefracture hysteresis of steel members. J. Struct. Eng. 2004, 130, 752-761. [CrossRef]

8. Mendes, L.A.; Castro, L.M. A simplified reinforcing steel model suitable for cyclic loading including ultra-low-cycle fatigue effects. Eng. Struct. 2014, 68, 155-164. [CrossRef]

9. Nip, K.H.; Gardner, L.; Davies, C.M. Extremely low cycle fatigue tests on structural carbon steel and stainless steel. J. Constr. Steel Res. 2010, 66, 96-110. [CrossRef]

10. Huang, X.W.; Tong, L.W.; Zhou, F. Prediction of fracture behavior of beam-to-column welded joints using micromechanics damage model. J. Constr. Steel Res. 2013, 85, 60-72. [CrossRef]

11. Bleck, W.; Dahl, W.; Nonn, A. Numerical and experimental analyses of damage behavior of steel moment connection. Eng. Fract. Mech. 2009, 76, 1531-1547. [CrossRef]

12. Xue, L. A unified expression for low cycle fatigue and extremely low cycle fatigue and its implication for monotonic loading. Int. J. Fatigue 2008, 30, 1691-1698. [CrossRef]

13. Kermajani, M.; Malek Ghaini, F.; Miresmaeili, R.; Aghakouchak, A.A.; Shadmand, M. Effect of weld metal toughness on fracture behavior under ultra-low cycle fatigue loading (earthquake). Mater. Sci. Eng. A 2016, 668, 30-37. [CrossRef]

14. Zhang, Q.B.; Zhang, J.X.; Zhao, P.F.; Huang, Y.; Yu, Z.H.; Fang, X.Y. Low-cycle fatigue behaviors of a new type of $10 \% \mathrm{Cr}$ martensitic steel and welded joint with Ni-based weld metal. Int. J. Fatigue 2016, 88, 78-87. [CrossRef]

15. Zhou, H.; Wang, Y.Q.; Shi, Y.J.; Xiong, J.; Yang, L. Extremely low cycle fatigue prediction of steel beam-to-column connection by using a micro-mechanics based fracture model. Int. J. Fatigue 2013, 48, 90-100. [CrossRef] 
16. Tateishi, K.; Hanji, T.; Minami, K. A prediction model for extremely low cycle fatigue strength of structural steel. Int. J. Fatigue 2007, 29, 887-896. [CrossRef]

17. Liao, F.F.; Wang, W.; Li, W.C.; Zhou, T.H. Review on research status of connection fracture of steel structures. J. Archit. Civ. Eng. 2016, 33, 67-75.

18. Coffin, L.F.J. A study of the effects of cyclic thermal stresses on a ductile metal. Trans. ASME 1954, 76, 931-950.

19. Manson, S.S. Behavior of Materials under Conditions of Thermal Stress; University of Michigan: Ann Arbor, MI, USA, 1953; pp. 1-37.

20. Kuroda, M. Extremely low cycle fatigue life prediction based on a new cumulative fatigue damage model. Int. J. Fatigue 2002, 24, 699-703. [CrossRef]

21. Huang, X.W.; Zhang, X.; Miao, T.C. A damage prediction model for ultra low cycle fatigue failure of building structural steel. Eng. Mech. 2017, 34, 101-108. [CrossRef]

22. Xing, J.H.; Guo, C.L.; Li, Y.Y.; Chen, A.G. Damage coefficient identification of micromechanical fracture prediction models for steel Q235B. J. Harbin Inst. Technol. 2017, 49, 184-188.

23. Hancock, J.W.; Mackenzie, A.C. On the mechanics of ductile failure in high-strength steel subjected to multi-axial stress-states. J. Mech. Phys. Solids 1976, 24, 147-169. [CrossRef]

24. Adasooriya, N.D.; Siriwardane, S.C.; Ohga, M. A simplified approach to predict the failure of steel members under interaction effect of fracture and fatigue. Int. J. Fatigue 2013, 47, 161-173. [CrossRef]

25. Liao, Y.H.; Xie, X.; Tang, Z.Z. Low cycle fatigue properties and fracture mechanism of Q345qC steel and its welded joint. J. Zhejiang Univ. 2018, 52, 73-81. [CrossRef]

26. Li, S.L.; Xie, X.; Liao, Y.H. Improvement of cyclic void growth model for ultra-low cycle fatigue prediction of steel bridge piers. Materials 2019, 12, 1615. [CrossRef]

27. Girão Coelho, A.M. Rotation capacity of partial strength steel joints with three-dimensional finite element approach. Comput. Struct. 2013, 116, 88-97. [CrossRef]

28. Cheng, G.; Zuo, J.; Lou, Z. Continuum damage model of low-cycle fatigue and fatigue damage analysis of welded joint. Eng. Fract. Mech. 1996, 55, 155-161. [CrossRef]

29. Tian, Q.; Zhuge, H.Q.; Xie, X. Prediction of the ultra-low-cycle fatigue damage of Q345qc steel and its weld joint. Materials 2019, 12, 4014. [CrossRef]

30. Bonora, N. A nonlinear CDM model for ductile failure. Eng. Fract. Mech. 1997, 58, 11-28. [CrossRef]

31. Kanvinde, A.M.; Deierlein, G.G. Cyclic void growth model to assess ductile fracture initiation in structural steels due to ultra low cycle fatigue. J. Eng. Mech. 2007, 133, 701-712. [CrossRef]

32. Chaboche, J.L. Time independent constitutive theories for cyclic plasticity. Int. J. Plast. 1986, 2, 149-188. [CrossRef]

33. Liao, Y.H. Research on Ultra Low Cycle Fatigue Properties and Fracture Mechanism of Steel Bridge Welded Joint. Master's Degree Thesis, Zhejiang University, Hangzhou, China, 2018. 